\title{
Novel Psychoactive Substances: Systematic Review and Evidence-Based Analysis of Literature
}

\author{
Ahmed Al-Imam ${ }^{1,2} \&$ Ban A. AbdulMajeed ${ }^{3}$ \\ ${ }^{1}$ Department of Postgraduate Medicine, School of Life and Medical Sciences, University of Hertfordshire, United \\ Kingdom \\ ${ }^{2}$ Department of Anatomy and Cellular Biology, College of Medicine, University of Baghdad, Iraq \\ ${ }^{3}$ Department of Pathology and Forensic Medicine, College of Medicine, Al-Nahrain University, Iraq \\ Correspondence: Dr Ahmed Al-Imam, House 18/5, Al-Akhtal Street, District 318, Al-Adhamyia, 10053, Baghdad, \\ Iraq. E-mail: tesla1452@gmail.com; a.m.al-imam@herts.ac.uk
}

Received: July 25, 2017 Accepted: August 17, 2017 Online Published: September 18, 2017

doi:10.5539/gjhs.v9n11p1 URL: https://doi.org/10.5539/gjhs.v9n11p1

\begin{abstract}
Background: The research output within the discipline of novel psychoactive substances (NPS) has been evolving since the end of the last decade. The introduction of the concept of evidence-based Medicine led to a revolutionary growth of all fields of medical research. The enhancements of research quality were also paralleled by the development of tools for critical analysis of literature.

Materials and Methods: The aim of the study is to assess the NPS research output, by means of evaluation of the level-of-evidence and the implemented statistical analyses. An extensive database of near 600 published manuscript was created; the papers were selected from the PubMed/Medline database by using pre-specified keywords. Each manuscript will be systematically scanned for; the first author, research institution, country, year of publication, type of study, statistical analysis, level-of-evidence, and journals of publication. Research efforts from the Middle East were also observed and quantified.
\end{abstract}

Results: Teams of NPS researchers included members in the range of one to twenty-nine, with and an average of 4.75 authors per publication. Research output was densely mapped in the developed countries including the UK $(53 \%)$, US (19\%), Italy (14\%), Germany (14\%), and Sweden (10\%); the Middle East contribution was minimal $(<1 \%)$. The top two research institutes were; King's College London (UK) and Sapienza University of Rome (Italy). Studies included; Cross-sectional analyses (15\%), Reviews (18\%), and Analytic chemistry (36\%). A considerable number of publications (34\%) had no statistics at all, while only $14 \%$ had inferential statistics. Top journals of publication were; Journal of Psychopharmacology, Current Neuropharmacology, and Drug and Alcohol Dependence.

Conclusion: Research output should always be assessed for quality control purposes. This study represents an innovative and systematic method of critical analysis of NPS literature. Future study efforts should be respondent to this study to achieve a better quality of research.

Keywords: Novel Psychoactive Substances, New Psychoactive Substances, NPS, Evidence-Based Medicine, Statistical Analysis, Quality Control

\section{Background}

The growth of novel psychoactive substances (NPS) and drug (ab)use problem was phenomenal in the past decade; it was also paralleled by efforts of NPS researchers (Krabseth et al., 2016; Orsolini et al., 2016; Wood et al., 2012). Regulating bodies for NPS include the United Nations Office on Drugs and Crime (UNODC), European Monitoring Centre for Drugs and Drug Addiction (EMCDDA), World Anti-Doping Agency (WADA), World Health Organization (WHO), and Food and Drug Administration (FDA) (Griffiths et al., 1997; Hanstad et al., 2008; Mackey \& Liang, 2013). These global organisations aim to interfere at legislation levels and policy making to either control or completely ban a particular substance (Ayres et al., 2012).

Researchers in the field of NPS are from multiple backgrounds, involving multiple disciplines; these are not limited to analytic chemistry, molecular biology, toxicology, biostatistics and data science, web analytics, animal 
modelling, and neuroscience (Dargan \& Wood, 2013). All these disciplines are interlinked with each other; researchers of NPS should be integrative and open-minded. Hence, a multi-talented scholar represents an outstanding unit and an essential building block of an active research team (Marcus, 2002; Smith and Robert, 2014). It is also highly appreciable that an NPS researcher is confident of his analytic tools, particularly the tools of data science and inferential statistics. The research attempts to counteract and analyse the NPS diffusion can be traced back to the end of the last decade (Wood et al., 2010). Researchers should be adequately communicated to share their expertise and research efforts on a global scale (Goldacre et al., 2000; Simon et al., 2000; Wong et al., 2000). PubMed/Medline is considered as a representative universal database for the scholarly published literature (Hsu, 2002; Vibert et al., 2009). This study will explore PubMed database in a systematic way for publications in connection with NPS as far back as 2010.

The introduction of the concepts of evidence-based Medicine (EBM) was revolutionary; it made it possible to backup the presented data with a hierarchy of authentication (evidence) (Davidoof et al., 2005; Sackett et al., 2006). The hierarchy is a pyramidal structure where anecdotal studies are at the bottom, while at the top there are the rigorous randomised controlled trials (RCTs) and metanalytic studies including the systematic reviews (CEBM, 2009). This study is based on an Internet snapshot of PubMed database with a succeeding retrospective longitudinal analysis of publications. The aim of this systematically thorough analysis is to infer the overall characteristics of NPS research, its strength, limitations, and defects; once these are known, errors can be avoided in the future. The analysis will focus primarily on three main themes; geographic distribution of NPS research institutes and researchers (1), the implemented tools of data science (2), and the level-of-evidence (3).

\section{Materials and Methods}

PubMed/Medline has been systematically searched for publications specific to the discipline of NPS. The aim of the search was to establish a database which is representative of the majority of publications on NPS research globally. Specific keywords were used; novel psychoactive substances (1), novel psychoactive substance* (1), new psychoactive substance (3), new psychoactive substance* (4), and (novel psychoactive substance*) OR (new psychoactive substance*) (5). The systematic search process was carried out in January and February 2017; the use of the keywords and the boolean operator (OR) was intended to expand the number of hits (publications) found on PubMed. Furthermore, no filters were used, in an attempt to avoid biases towards; geographic location, researchers, date of publication, or countries (of research institution). Only one duplicate article was found and then excluded. Hence, the number of hits (publications indexed in PubMed) were sufficient in quantity and topography; thus reliable enough to deduct a statistical inference in relation to the overall trends and quality of NPS-related research output back to the earliest attempts of research found in the year 2010.

The typology of this observational analysis is retrospective. Back in 2010, few studies on NPS existed; NPS research was still in its infancy. This was followed later by an exponential growth of publications, paralleled by the more escalating growth of the NPS "industry" and its collateral e-phenomenona. This analysis will aim to provide a snapshot for the existing body of literature by criticising its strength, potential weaknesses, and limitations. The critics will be the tools of evidence-based Medicine (EBM) and critical appraisal of literature (CEBM, 2009; Norman and Shannon, 1998; Reynolds, 2008). The number of hits retrieved from PubMed will be used to compile an extensive database made of nine tabulated parameters; number of authors per a publication (1), name of the $1^{\text {st }}$ author (2), the research institute of $1^{\text {st }}$ author (3), country of the research institute (4), year of publication (or indexing) in PubMed (5), type of the study (6), type of the implemented statistical analysis (7), the level-of-evidence (8), and the journal of publication (9). The categorization of the level-of-evidence will be based on the classification system implemented by the Oxford Centre for Evidence-Based Medicine (CEBM, 2009), and CASP appraisal tools (Norman and Shannon, 1998; Rosenberg and Donald 1995). The CASP analysis will be based on reading through each article (title, abstract, and full length), with a particular focus on; the nature of the study, and the application of biostatistics and data science methodologies. The implemented statistics will be categorised into; none, descriptive, and inferential (Spriensma, 2016). The level-of-evidence will be ranging from 5 (weakest evidence) to 1 (strongest evidence). This holistic analysis will enable us to; derive a "formula" on the global and regional research within the discipline of NPS, conclude the major contributing countries to the research output, and apprehend the average level-of-evidence.

The primary objective is to assess if the retrospective research output was up to the expectation (of substantial evidence), and to understand the potential limitations. There will also be attempts to correlate the geographical distribution of the publications with the diffusion (spread) of NPS on the e-markets of the darknet to; reach a conclusion if the research output is keeping pace with the NPS phenomenon on the deep web and if there are sufficient research activities from the Middle Eastern and Arabic countries. 


\section{Results and Discussion}

At the moment the snapshot was taken, the total number of hits (publications) was 587. The majority of authors were from the developed countries, particularly from Europe, the United States (US), and the United Kingdom (UK). Publications from the Middle East, including Arabic and Islamic countries, were scarce. The number of authors per a single publication ranged from one (minimum) to 29 (maximum), the average number of authors (per publication) was $4.75(+/-) 2.99$, both the median and the mode values for the number of authors (per publication) was four (4). The number of authors was analysed using a Q-Q plot and Box plot presentation; statistical outliers were evident in which the number of authors per a publication was more than ten (10); these outliers represent exceptional cases of the abundance of NPS researchers (per a particular published research).

The outliers included; Corazza et al., 2013 (UK); Bade at al., 2017 (Spain); Deluca et al., 2012 (UK); Giese et al., 2015 (Sweden); Martinotti et al., 2014 (Italy); Cinosi et al., (UK, Italy); Brandt et al., 2014 (UK); Caloro et al., 2016 (Italy); Yun et al., 2016 (Republic of Korea); Acton et al., 2014 (Austria); McLaughlin et al., 2014 (Ireland); McLaughlin et al., 2017 (Ireland); Tanibuchi et al., 2017 (Japan); McLaughlin et al., 2016 (Ireland); Wohlfarth et al., 2016 (Sweden); Togari et al., 2016 (Japan); Vento et al., 2014 (Italy); Daveluy et al., 2016 (France); Brandt et al., 2017 (UK); Negishi et al., 2015 (Japan); McLaughlin et al., 2016 (Ireland); Lanza at al., 2015 (Austria); Simonsen et al., 2015 (Denmark); Parrott et al., 2013 (UK); Bersani et al., 2014 (UK); Lanza at al., 2013 (Austria); and Murray et al., 2012 (Ireland). Apparently, the majority of those authors are from Europe particularly from the UK and Italy; few are from Asia.

The research institutes at which these NPS studies were conducted, took place in Europe, notably the UK, Italy, and the US. A Box plot presentation of the number of publications per research institute shows that exceptional institutes (statistical outliers) had a minimum of four publications per Institute. The top 10 research institute (Figure 1 and 2) for research output (in an ascending order); King's College London (UK), Sapienza University of Rome (Italy), Liverpool John Moores University (UK), University of New South Wales (UK), University of Hertfordshire (UK), Massey University (New Zealand), Karolinska Institutet (Sweden), National Institutes of Health (US), Guy's and St Thomas' NHS Foundation Trust and King's Health Partners (UK), and Saarland University (Germany).

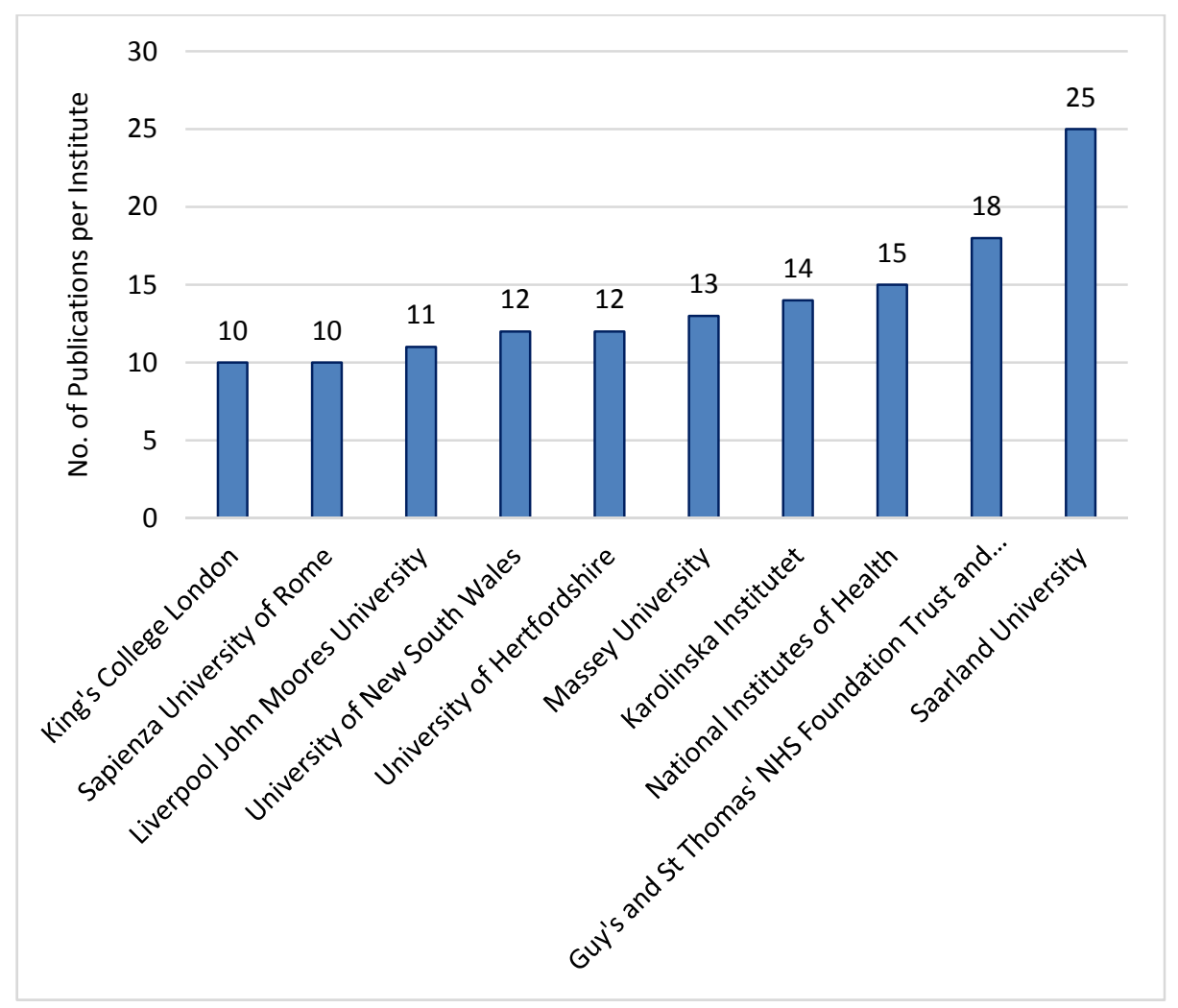

Figure 1. Top Ten Institutes for NPS-related Research 


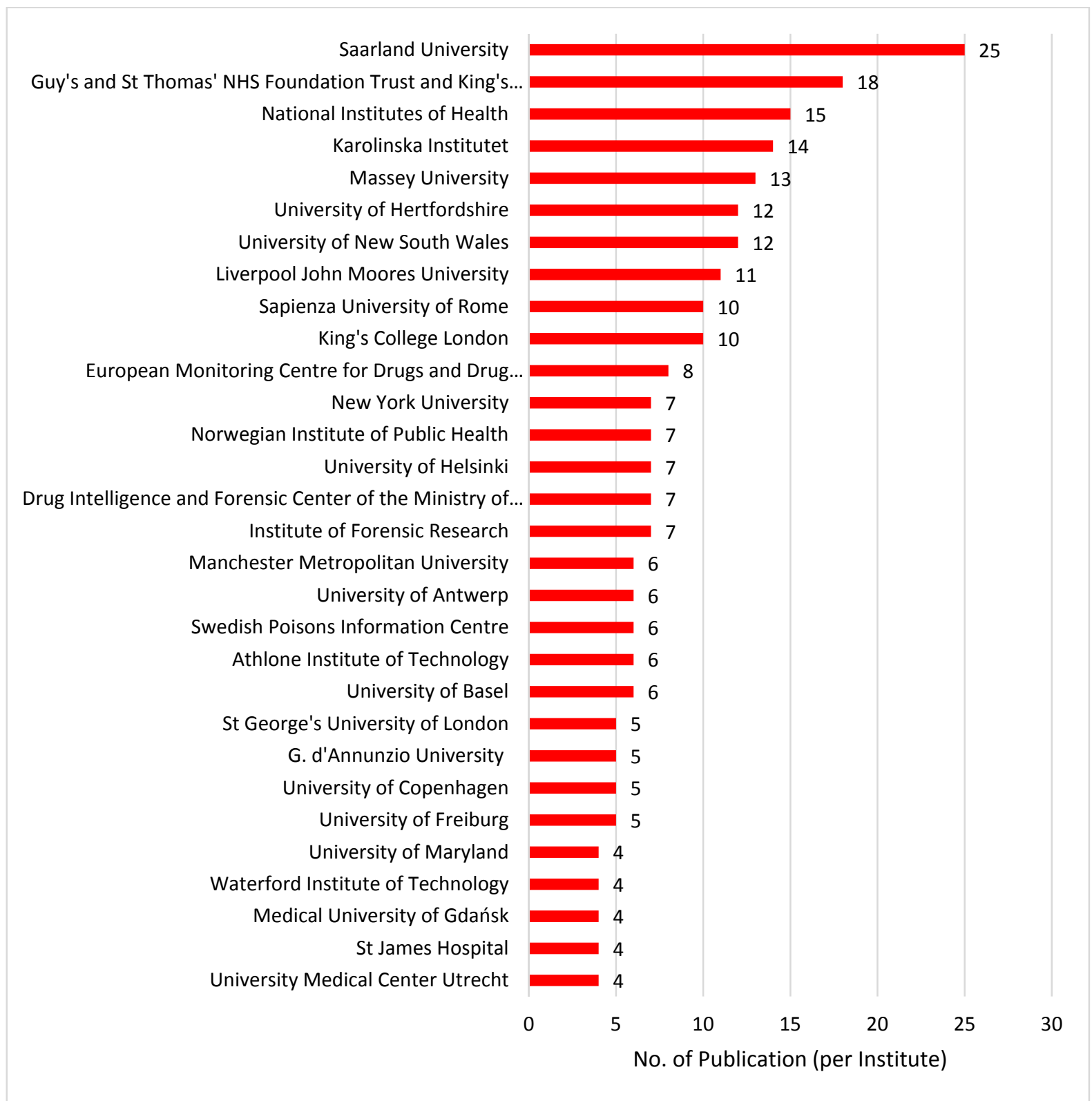

Figure 2. Top NPS Research Institutes

On the other hand, research output by country led to similar results; some countries had a profound research output (Figure 3); outstanding contributors (statistical outlier) were observed strictly in countries from Europe and North America, with a minimum of 31 publications per country, these countries are; UK (43\%), US (19\%), Italy (14\%), Germany (14\%), and Sweden (10\%). It is striking that countries from the Middle East (Figure 4), including Iraq and Iran, contributed the least to the overall research output (less than 1\%); this paucity in production (research output) is, of course, outpaced by the escalating pace of the NPS "industry" in the same geographic region (Middle East) (Al-Hemiary et al., 2014; Al-Imam et al., 2016; Al-Imam, 2017; Al-Imam et al., 2017). Contributing countries from the Middle East included; Israel, Iran, Cyprus, and Iraq; other contributing Arabic countries included Qatar and Algeria. Similarly, based on the sum of the number of authors (per publication), the developed countries contributed the most. Furthermore, it has been hypothesised that the count of $1^{\text {st }}$ authors and the sum of authors are positively correlated with each other, particularly in the developed countries. Hence, linear regression was carried out to test the hypothesis, which was confirmed to be accurate $\left(R^{2}\right.$ score $\left.=0.987\right)$. 


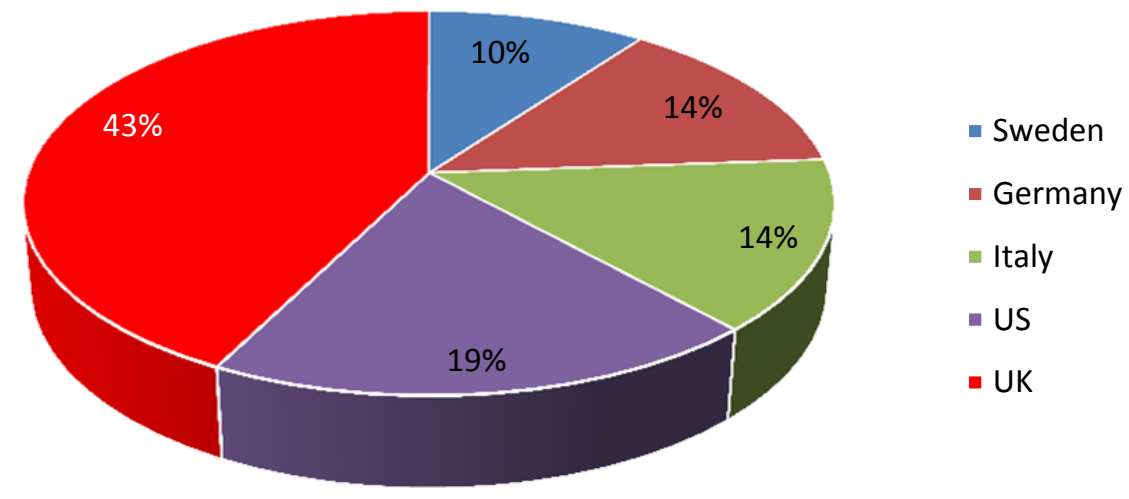

Figure 3. Research Output by Country: Top Five Countries 


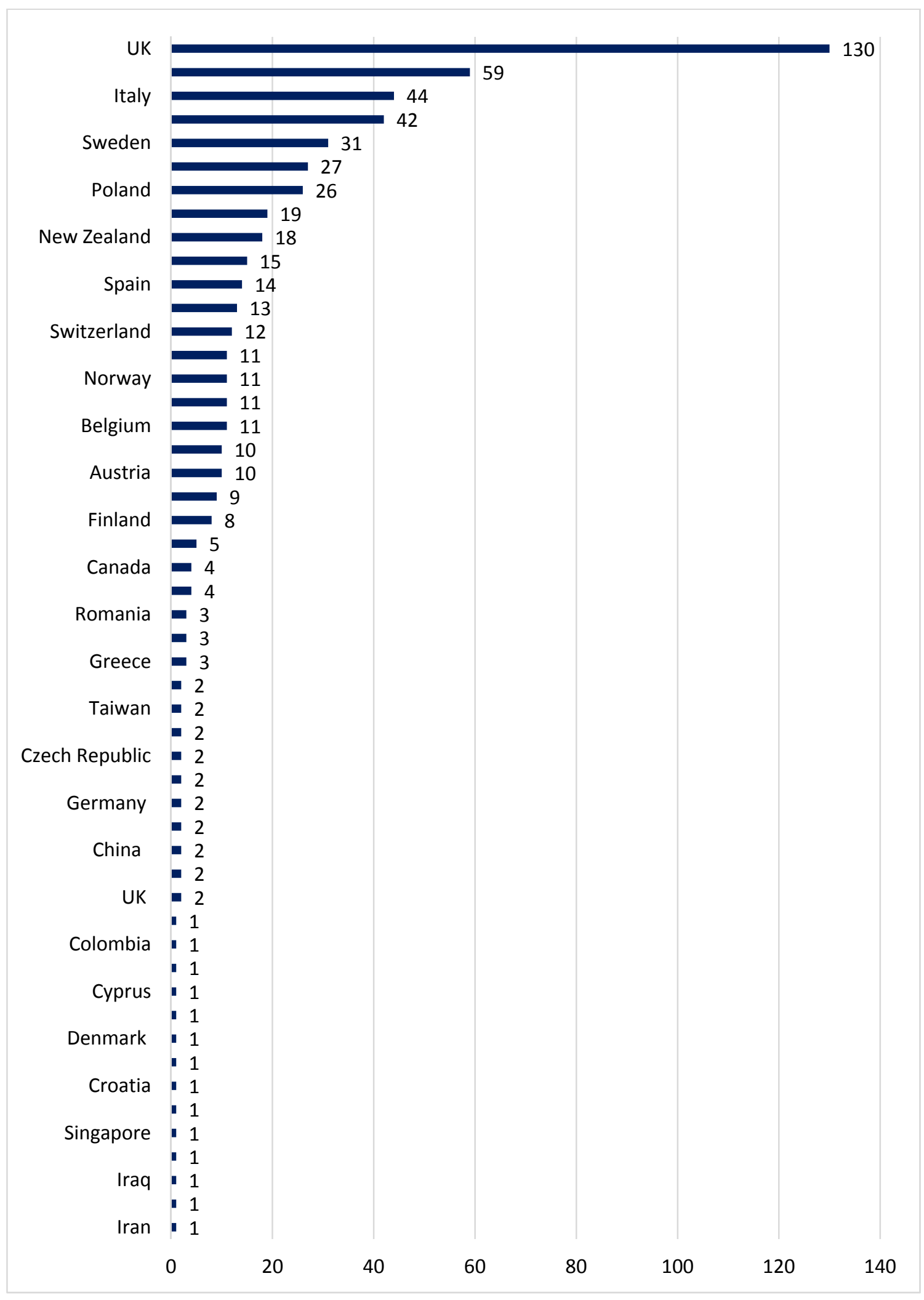

Figure 4. Research Output by Country 
Analysis of the implemented Statistic (Figure 5 and 6) revealed that almost half of the NPS studies have only basic (descriptive) statistics, while nearly one-third of the total research output (34\%) had no statistics at all (None), and only $14 \%$ implemented advanced (inferential) statistics. The lack of application of inferential statistics is a critical defect in relation to the original research activities of NPS. Without these statistical inferences, valid and generalizable conclusions in relation to the studied population cannot be made. The level-of-evidence was also assessed in parallel to the assessment of the implemented statistics. The majority of studies in which either descriptive or inferential statistics were applied, were mostly of level-3b or 2b. On the other hand, studies in which no statistic was implemented, were mostly of level-3a or 5. In relation to the level-of-evidence, studies has contributed as follows; level-3b (50\%), level-3a (19\%), level-5 (17\%), level-2b (12\%), and other studies (level-1a, $1 \mathrm{~b}, 1 \mathrm{c}$, and $2 \mathrm{a}$ ) contributed to no more than $2 \%$ of the total. Furthermore, linear regression analysis shows some degree of positive $(+\mathrm{ve})$ correlation $\left(\mathrm{R}^{2}=0.047\right)$ between the type of the implemented statistical analysis and the overall level-of-evidence of the publications.

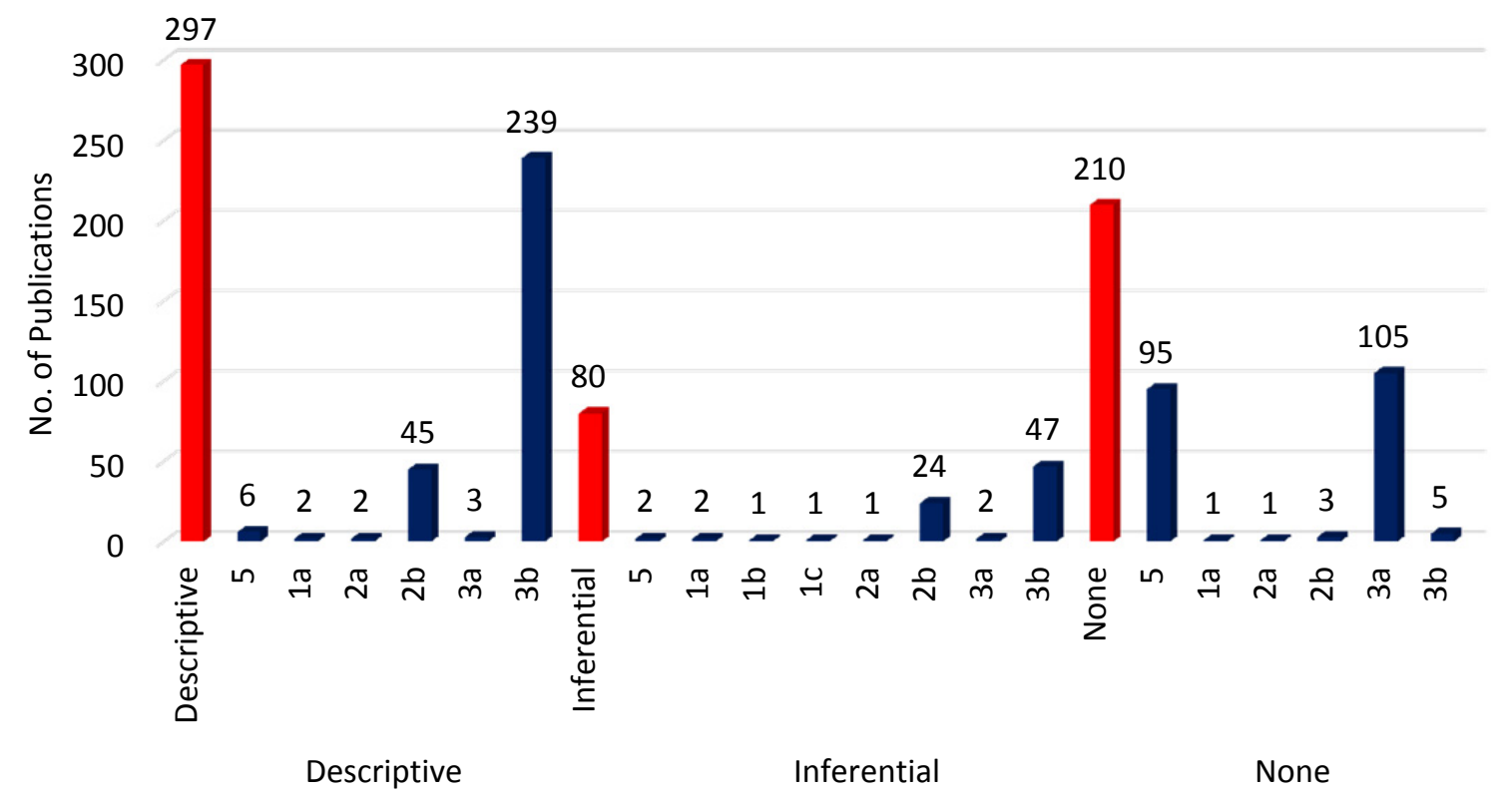

Figure 5. NPS Research Output (2010-2017): Implementation of Statistic versus Level-of-Evidence 


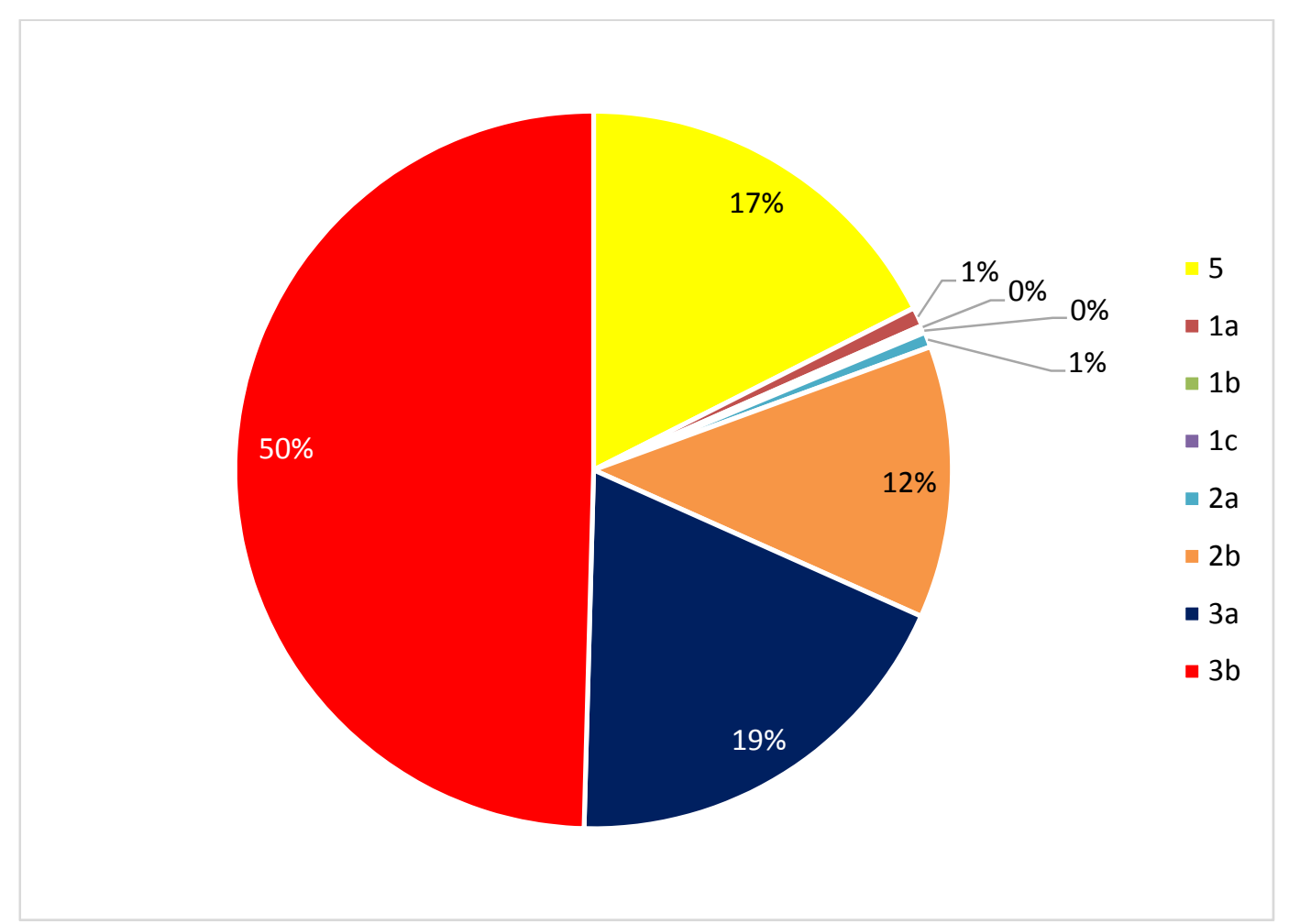

Figure 6. Level-of-Evidence: Retrospective Analysis (2010-2017)

The type of studies included (in a descending order of frequency); analytic chemistry studies, reviews, observational cross-sectional, retrospective, case reports, case series, commentaries, molecular biology and analytic chemistry, editorials, policy analysis, perspectives, letters, systematic reviews, animal studies, book chapters, observational retrospective and cross-sectional, RCTs, short communications, hybrid studies, observational prospective studies, case-control studies, continuous professional development (CPDs), analytic chemistry and bacteriology, case registry, systematic review protocol, quasi-experimental studies, and communications. The top ten types of studies (Figure 7) in ascending order were; Policy analysis (2\%), Editorial (3\%), Molecular biology and analytic chemistry (3\%), Commentary (3\%), Observational case series (4\%), Case report (7\%), Retrospective study (9\%), Observational cross-sectional study (15\%), Review (18\%), and Analytic chemistry $(36 \%)$. 


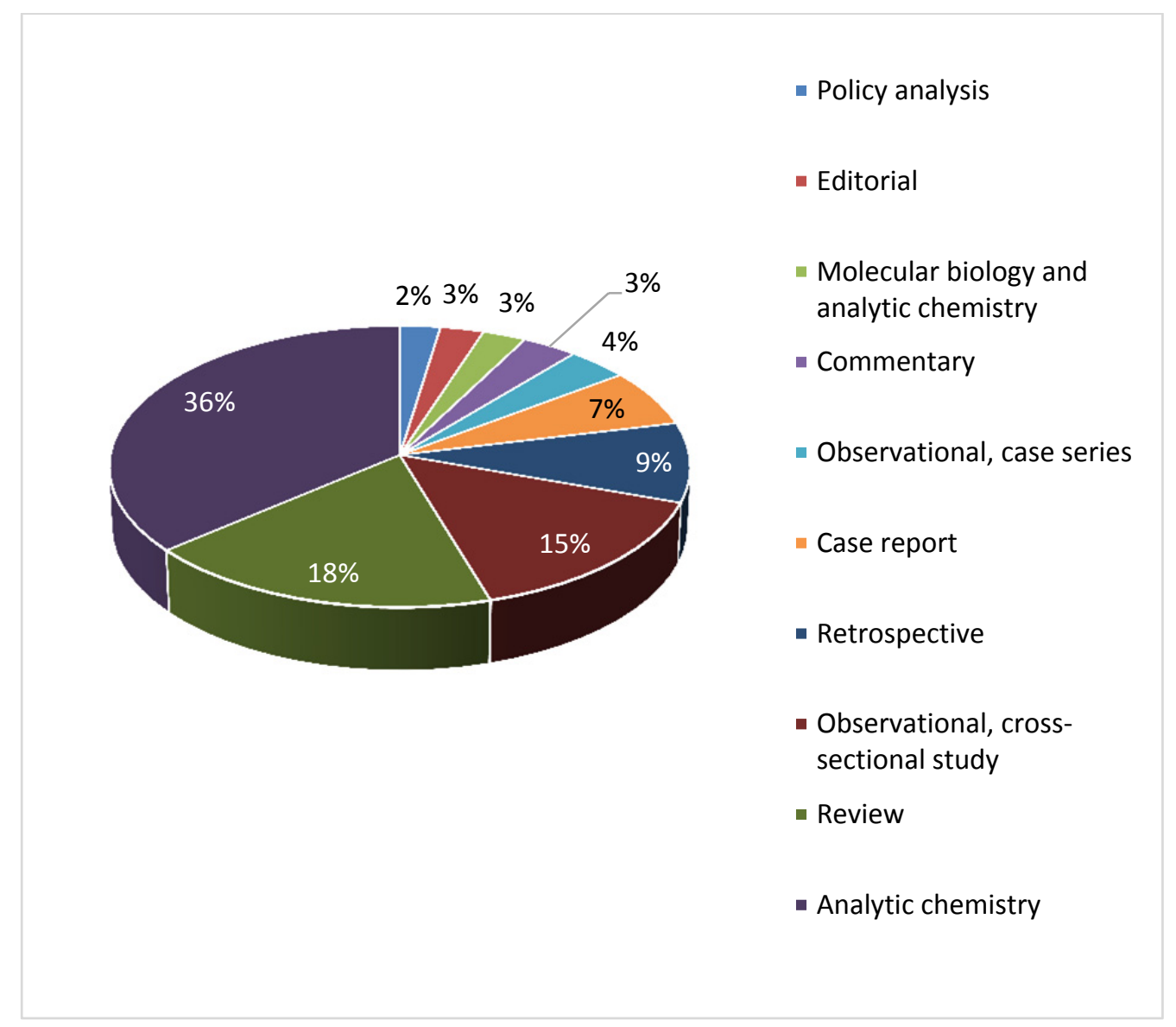

Figure 7. Top Ten Types of Studies in NPS Research

NPS research output was also categorized based on the different regions of the world (Figure 8); Africa (less than $1 \%)$, Middle East (1\%), South America (2\%), UK (5\%), Australasia (6\%), Asia (8\%), North America (10\%), and Europe excluding the UK (68\%). The analysis of variance (one way-ANOVA) displayed a clear leverage of Europe over other regions ( $p$-value $<0.001)$. Apparently, the contribution of researchers from Middle East, Asia, and Africa was minimal. Furthermore, the frequency of usage of the deep web and the e-markets on the darknet was found to be compatible with the geographic distribution of researchers in the developed world (Figures 9 and $10)$.

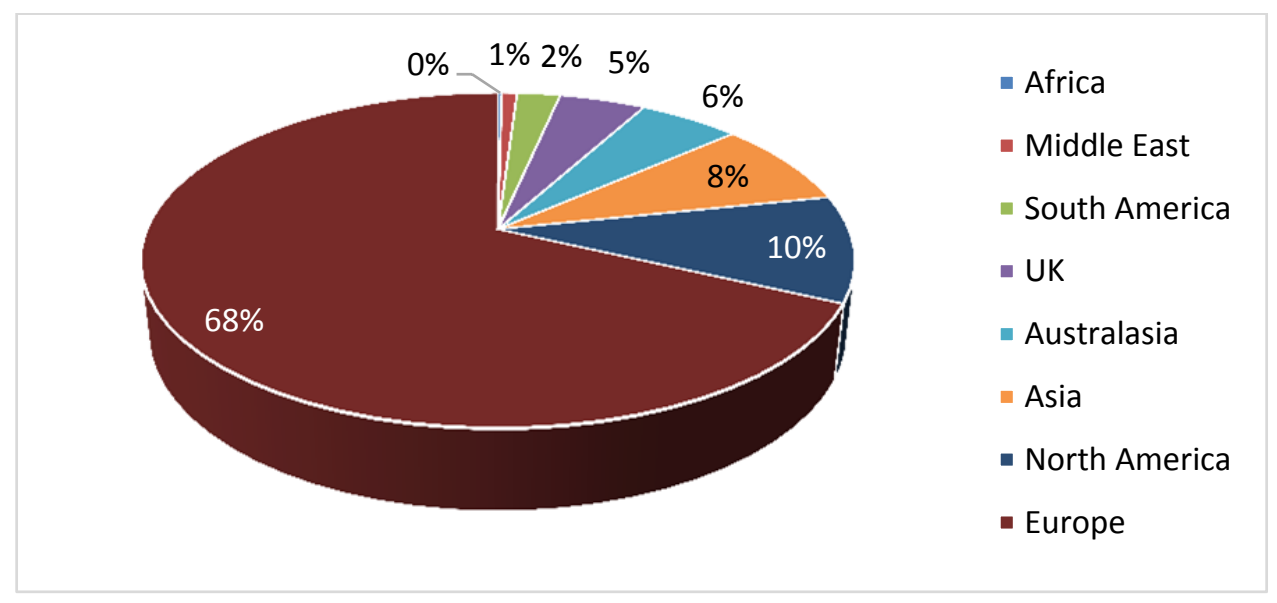

Figure 8. The Regional Geographic Mapping of NPS Research (2010-2017) 


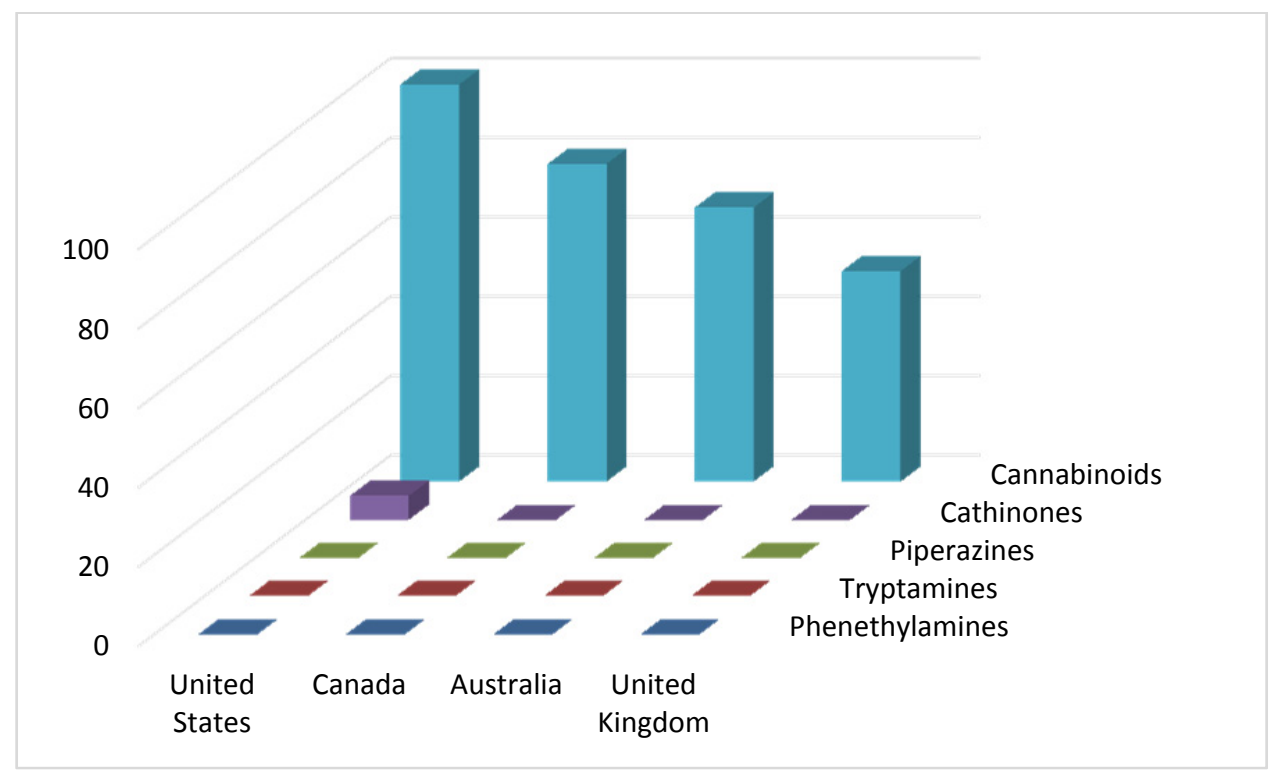

Figure 9. Google Trends Analyses for Chemical Categories of NPS (2012-2016)

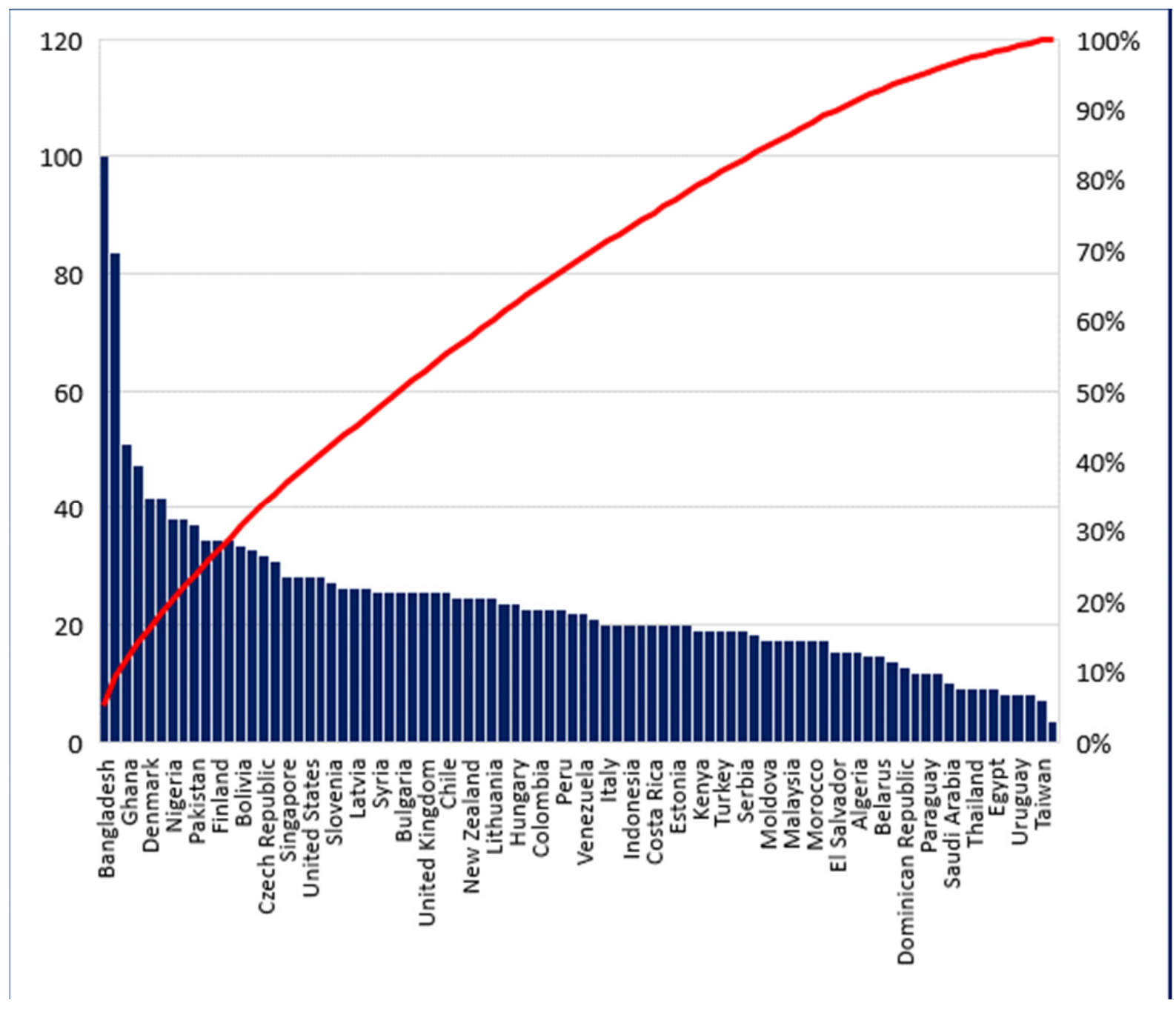

Figure 10. Deep Web Usage by Geographic Location 
The outlet (Journal of publications) for NPS research were highly numerous and diverse (Figure 11). The top ten journals (in ascending order); Journal of Psychopharmacology (3\%), Current Neuropharmacology (3\%), Drug and Alcohol Dependence (3\%), Human Psychopharmacology (7\%), Analytical and Bioanalytical Chemistry (9\%), International Journal of Drug Policy (9\%), Addiction (10\%), Clinical Toxicology (12\%), Forensic Science International (13\%), and Drug Testing and Analysis Journal (31\%). Drug Testing and Analysis Journal published almost one-third (31\%) of the total research output; this high percentage seems to be concordant with the fact that one-third (33\%) of NPS research output is in relation to the discipline of the analytic chemistry (Ayres, 2012; Gibbons, 2012; Kinyua, 2015).

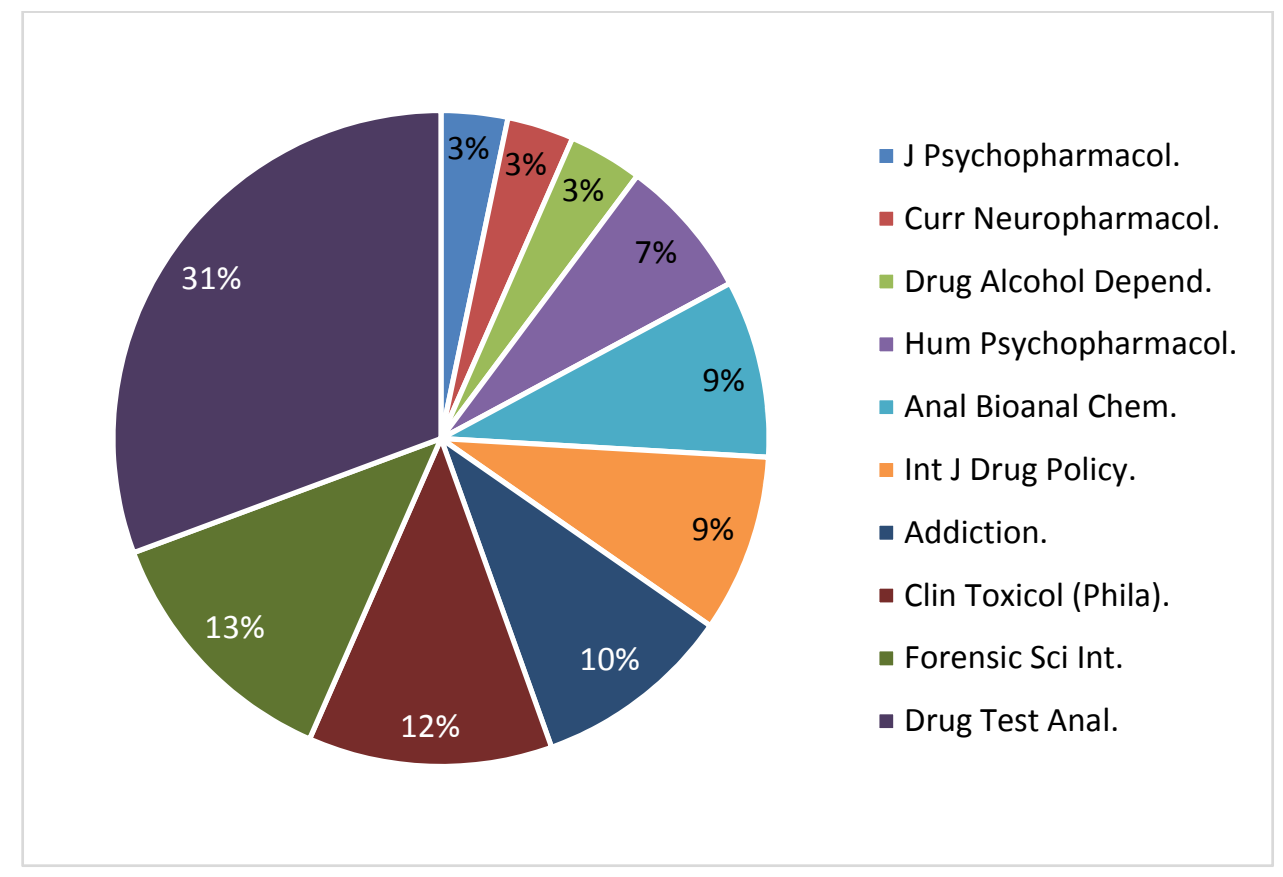

Figure 11. The Most Popular Journal for Publication of NPS Research (2010-2017)

To re-encapsulate, it is ostensible that NPS researchers are densely populated in the developed parts of the world, namely western Europe and the UK, North America, and Australasia. Europe is in the lead. Among all countries, the United Kingdom appears to have the biggest contribution in relation to the number of; NPS researchers, publications, and research institutes.

\section{Conclusion}

The phenomenon of NPS and its e-commerce has spread beyond international borders; it is not limited to a particular region of the world, neither developed nor developing. On the other hand, it is ostensible that NPS researchers are densely populated in the developed parts of the world, namely in western Europe and North America. Europe is in the lead; the United Kingdom and Italy have the biggest share of researchers, publications, and research institute in connection to NPS.

The level-of-evidence of the analysed body of literature was not satisfactory, and on top, the implementation of statistics was not always inferential. The lack of statistical inference is a big waste and a significant threat to the quality of the research efforts. Unfortunately, in the region of the Middle East and other Arabic-Islamic countries, the level of research is still primitive and constitute no more than few hundredth of the total research output and publications. Furthermore, regulating bodies are either lacking or defective; legal status and legislative actions are often blurred.

Future research efforts should focus on the effective integration of data science methods, with an aim to strengthen the embedded level-of-evidence. Training of researchers from the Middle East and other developing countries will be fruitful to fight this dangerous phenomenon; it will also fortify the public health and the economy from the daring threats of the NPS industry. Potentials for data mining, also known as knowledge discovery in databases (KDD), are also indispensable; these can be deployed for real-time and systematic analyses of the published literature databases. 


\section{Competing Interests Statement}

The authors have nothing to be declared.

\section{Source of Funding}

This study was entirely self-funded.

\section{References}

Al-Hemiary, N. J., Al-Diwan, J. K., Hasson, A. L., \& Rawson, R. A. (2014). Drug and alcohol use in Iraq: findings of the inaugural Iraqi Community Epidemiological Workgroup. Substance use \& misuse, 49(13), 1759-1763. https://doi.org/10.3109/10826084.2014.913633

Al-Imam, A. (2017). Could Hallucinogens Induce Permanent Pupillary Changes in (Ab) users? A Case Report from New Zealand. Case Reports in Neurological Medicine, 2017. https://doi.org/10.1155/2017/2503762.

AL - Imam, A., Santacroce, R., Roman - Urrestarazu, A., Chilcott, R., Bersani, G., Martinotti, G., \& Corazza, O. (2017). Captagon: use and trade in the Middle East. Human Psychopharmacology: Clinical and Experimental, $32(3)$.

Al-Imam, A., Simonato, A. P., \& Corazza, O. (2016). Haloperidol, an old antipsychotic with potential use by NPS users in Iraq. Research and Advances in Psychiatry, 3(3), 81-84. Retrieved from https://www.rapjournal.eu/materiale_cic/948_3_3/8031_haloperidol/article.htm

Ayres, T. C., \& Bond, J. W. (2012). A chemical analysis examining the pharmacology of novel psychoactive substances freely available over the internet and their impact on public (ill) health. Legal highs or illegal highs?. BMJ open, 2(4), e000977. https://doi.org/10.1136/bmjopen-2012-000977

CEBM. Oxford Centre for Evidence-based Medicine - Levels of Evidence (March 2009). Retrieved 3 March, 2017, from http://www.cebm.net/oxford-centre-evidence-based-medicine-levels-evidence-march-2009/

Dargan, P., \& Wood, D. (Eds.). (2013). Novel psychoactive substances: classification, pharmacology and toxicology. Academic Press.

Davidoff, F., Haynes, B., Sackett, D., \& Smith, R. (1995). Evidence based medicine. BMJ: British Medical Journal, 310(6987), 1085. https://doi.org/10.1136/bmj.310.6987.1085

Gibbons, S. (2012). 'Legal highs'-novel and emerging psychoactive drugs: a chemical overview for the toxicologist. Clinical Toxicology, 50(1), 15-24. https://doi.org/10.3109/15563650.2011.645952

Goldacre, M., Kurina, L., Yeates, D., Seagroatt, V., \& Gill, L. (2000). Use of large medical databases to study associations between diseases. Qjm, 93(10), 669-675. https://doi.org/10.1093/qjmed/93.10.669

Griffiths, P., Vingoe, L., Jansen, K., Sherval, J., Lewis, R., Hartnoll, R., \& Nilson, M. (1997). New trends in synthetic drugs in the European Union: epidemiology and demand reduction responses. Lisboa: EMCDDA.

Hanstad, D. V., Smith, A., \& Waddington, I. (2008). The establishment of the World Anti-Doping Agency: A study of the management of organizational change and unplanned outcomes. International review for the sociology of sport, 43(3), 227-249. https://doi.org/10.1177/1012690208100552

Hsu, P. P. (2002). Natural medicines comprehensive database. Journal of the Medical Library Association, 90(1), 114.

Kinyua, J., Covaci, A., Maho, W., McCall, A. K., Neels, H., \& Nuijs, A. L. (2015). Sewage - based epidemiology in monitoring the use of new psychoactive substances: Validation and application of an analytical method using LC - MS/MS. Drug testing and analysis, 7(9), 812-818. https://doi.org/10.1002/dta.1777

Krabseth, H. M., Tuv, S. S., Strand, M. C., Karinen, R. A., Wiik, E., Vevelstad, M. S., ... \& Vindenes, V. (2016). Novel psychoactive substances. Tidsskrift for den Norske laegeforening: tidsskrift for praktisk medicin, ny raekke, 136(8), 714-717. https://doi.org/10.4045/tidsskr.15.1278

Mackey, T. K., \& Liang, B. A. (2013). Improving global health governance to combat counterfeit medicines: a proposal for a UNODC-WHO-Interpol trilateral mechanism. BMC medicine, 11(1), 233. https://doi.org/10.1186/1741-7015-11-233

Marcus, B. (2002). The road of excess: A history of writers on drugs. Harvard University Press.

Norman, G. R., \& Shannon, S. I. (1998). Effectiveness of instruction in critical appraisal (evidence-based medicine) skills: a critical appraisal. Canadian Medical Association Journal, 158(2), 177-181. 
Orsolini, L., Papanti, D., Vecchiotti, R., Valchera, A., Corkery, J., \& Schifano, F. (2016). Novel psychoactive substances. European Psychiatry, 33, S59-S60. https://doi.org/10.1016/j.eurpsy.2016.01.945

Reynolds, S. (2008). Evidence-based practice: A critical appraisal. John Wiley \& Sons.

Rosenberg, W., \& Donald, A. (1995). Evidence based medicine: an approach to clinical problem-solving. Bmj, 310(6987), 1122-1126. https://doi.org/10.1136/bmj.310.6987.1122

Sackett, D. L., Rosenberg, W. M., Gray, J. M., Haynes, R. B., \& Richardson, W. S. (1996). Evidence based medicine: what it is and what it isn't.

Simon, G. E., Unützer, J., Young, B. E., \& Pincus, H. A. (2000). Large medical databases, population-based research, and patient confidentiality. American Journal of Psychiatry, 157(11), 1731-1737. https://doi.org/10.1176/appi.ajp.157.11.1731

Smith, C. D., \& Robert, S. (2014). 'Designer drugs': update on the management of novel psychoactive substance misuse in the acute care setting. Clinical Medicine, 14(4), 409-415. https://doi.org/10.7861/clinmedicine.14-4-409

Spriensma, A. (2016). Descriptive Versus Inferential Statistics. Journal of Endourology, 30(1), 1-4.

US National Library of Medicine, National Institutes of Health. (novel psychoactive substance*) OR (new psychoactive substance*). $\quad$ Retrieved 03 March 2017, from https://www.ncbi.nlm.nih.gov/pubmed/?term $=($ novel + psychoactive + substance* $)+\mathrm{OR}+($ new + psychoactive + substance*)

Vibert, N., Ros, C., Bigot, L. L., Ramond, M., Gatefin, J., \& Rouet, J. F. (2009). Effects of domain knowledge on reference search with the PubMed database: An experimental study. Journal of the Association for Information Science and Technology, 60(7), 1423-1447. https://doi.org/10.1002/asi.21078

Wong, M. L., Lam, W., Leung, K. S., Ngan, P. S., \& Cheng, J. C. (2000). Discovering knowledge from medical databases using evolutionory algorithms. IEEE Engineering in Medicine and Biology Magazine, 19(4), 45-55. https://doi.org/10.1109/51.853481

Wood, D. M., \& Dargan, P. I. (2012). Novel psychoactive substances: how to understand the acute toxicity associated with the use of these substances. Therapeutic drug monitoring, 34(4), 363-367. https://doi.org/10.1097/FTD.0b013e31825b954b

Wood, D. M., \& Dargan, P. I. (2012). Understanding how data triangulation identifies acute toxicity of novel $\begin{array}{lllll}\text { psychoactive drugs. Journal of Medical Toxicology, } & \text { 8(3), }\end{array}$ https://doi.org/10.1007/s13181-012-0241-3

Wood, D. M., Davies, S., Greene, S. L., Button, J., Holt, D. W., Ramsey, J., \& Dargan, P. I. (2010). Case series of individuals with analytically confirmed acute mephedrone toxicity. Clinical Toxicology, 48(9), 924-927. https://doi.org/10.3109/15563650.2010.531021

\section{Copyrights}

Copyright for this article is retained by the author(s), with first publication rights granted to the journal.

This is an open-access article distributed under the terms and conditions of the Creative Commons Attribution license (http://creativecommons.org/licenses/by/4.0/). 